\title{
Penerapan Tema Arsitektur Analogi Pada Perancangan Wahana Apresiasi Seni Kontemporer di Surabaya
}

\author{
Fitria Wulan Rahmawati ${ }^{1}$, Siti Azizah ${ }^{2}$, Esty Poedjioetami ${ }^{3}$ \\ 1,2,3Jurusan Arsitektur, Fakultas Teknik Sipil dan Perencanaan, Institur Teknologi Adhi Tama Surabaya \\ Email: ${ }^{1}$ fitriawulanr12@gmail.com
}

\begin{abstract}
The potential and opportunity for Surabaya to become a new art center in Indonesia is huge. But the art facility is not comparable enough with the potentials and opportunities that Surabaya has. To improve the contemporary art market in Indonesia, especially in the city of Surabaya, it is necessary to have a building as an appreciation facility for the people of Indonesia, especially Surabaya, for contemporary art. The method used is a qualitative method, which is a research method that provides an explanation using data analysis. The function of the building is intended as an entertainment and educational facility. The space program is divided into several facilities, including the main facilities (introduction, training, purchasing, community), supporting facilities, services, and management facilities. In this design, the theme carried is analogy architecture, which also applies contemporary elements as expressions of the form and function of the building. As well as contemporary macro concepts as representations of building functions as a medium for appreciation of contemporary art. Embodiment of the analogy to land use is realized by the use of integrated micro concepts. Whereas in the form of buildings, the embodiment of the analogy is applied using a dynamic micro concept which analogizes the free characteristic of contemporary art. And the application of analogy to space is realized by the concept of a flexible micro space, intended so that the existing art space can be changed according to needs and not fixed, so that it can display the realization of the art as maximum as it can be.
\end{abstract}

Keywords: Analogical Architecture; Apreciation Facility; Contemporary Art.

\begin{abstract}
Abstrak. Potensi dan peluang bagi Surabaya untuk menjadi kiblat seni baru di Indonesia sangat besar. Hanya saja wadah penuangan seni tidak sebanding dengan potensi dan peluang yang dimiliki. Untuk meningkatkan pasar seni kontemporer di Indonesia, khususnya Kota Surabaya, perlu adanya sebuah bangunan sebagai wahana atau wadah apresiasi masyarakat Indonesia, khususnya Surabaya, terhadap kesenian kontemporer. Metode yang digunakan adalah metode kualitatif, yaitu metode riset yang sifatnya memberikan penjelasan dengan menggunakan analisis data. Fungsi bangunan ditujukan sebagai fasilitas hiburan dan edukasi. Program ruang terbagi atas beberapa fasilitas, diantaranya, fasilitas utama (fasilitas pengenalan, pelatihan, pembelian, komunitas), fasilitas penunjang, servis, dan fasilitas pengelola. Pada perancangan ini, tema yang diusung yaitu arsitektur analogi, dimana juga menerapkan unsur kontemporer sebagai ekspresi wujud dan fungsi bangunan. Serta konsep makro kontemporer sebagai representasi fungsi bangunan sebagai wahana apresiasi seni kontemporer. Perwujudan analogi pada penataan lahan diwujudkan dengan penggunaan konsep mikro terintegrasi. Sedangkan pada bentuk bangunan, perwujudan analogi diterapkan menggunakan konsep mikro dinamis dimana menganalogikan sifat seni kontemporer yang bebas. Dan penerapan analogi pada ruang diwujudkan dengan konsep mikro ruang yang fleksibel, dimaksudkan agar ruang seni yang ada dapat diubah-ubah sesuai kebutuhan dan tidak tetap, sehingga dapat menampilkan perwujudan karya seni dengan maksimal.
\end{abstract}

Kata Kunci: Arsitektur Analogi, Seni Kontemporer, Wahana Apresiasi 


\section{Pendahuluan}

Menurut direktur Museum Rudi Isbandi, Rully Anwar, mengatakan bahwa gairah pasar seni rupa di Surabaya tercermin, antara lain, lewat transaksi di Pasar Seni Lukis Indonesia (PSLI) yang terus meningkat dari tahun ke tahun. Potensi dan peluang bagi Surabaya untuk menjadi kiblat seni baru di Indonesia sangat besar. Karya perupa kontemporer Indonesia banyak diminati oleh kolektor internasional. Hanya saja wadah penuangan seni tidak sebanding dengan potensi dan peluang yang dimiliki. Pameran seni yang diadakan setahun sekali saja tidak cukup untuk mengembangkan peluang Surabaya untuk dilirik dalam bisang seni sehingga kesenian kontemporer dapat berkembang dan tidak mati.

Dari sinilah muncul solusi yaitu dengan menciptakan sarana atau wadah permanen yang dapat menghadirkan karya-karya seniman kontemporer. Dengan adanya Wahana Apresiasi Seni Kontemporer ini dirasa dapat meningkatkan potensi pasar seni di Indonesia, khususnya Surabaya. Selain itu, juga dapat mengembangkan minat masyarakat terhadap seni, terutama seni kontemporer.

Wahana Apresiasi Seni Kontemporer ini dirancang untuk meningkatkan potensi Surabaya dalam pasar seni dan menjadikan Surabaya menjadi kiblat seni baru di Indonesia. Tak lepas dengan penggunaan tema rancangan arsitektur analogi yang menganalogikan seni kontemporer sebagai wujud dan fungsi bangunan. Dengan fasilitas-fasilitas yang mewadahi setiap pengunjung untuk memicu minat seninya.

\section{Tinjauan Pustaka}

\subsection{Pengertian Analogi}

Menurut Keith J. Holyoak dan Paul Thagard (dalam Zarzar, 2008:9), analogi dapat digunakan dengan bermacam cara, salah satunya adalah sebagai alat komunikasi seseorang di dalam mengekspresikan pemikirannya secara tidak langsung. Suatu benda dikatakan analog dengan benda lainnya apabila keduanya memiliki beberapa kesamaan. Analogi memiliki tiga hal dasar, yaitu kesamaan, struktur atau susunan, dan kegunaan. Analogi ditekankan untuk mengidentifikasi struktur atau sususan paralel antara sumber dan benda obyek. Setiap elemen benda obyek harus terhubung dengan hanya satu elemen pada sumber (dan sebaliknya). (Lucia Ina Trisjanti)

Analogi adalah salah satu pendekatan bentuk yang digunakan dalam desain arsitektur. Pendekatan analogi bukan hanya sekedar menjiplak bentuk objek alam yang dianalogikan, tapi diperlukan proses-proses analisis dan merangkainya sehingga menghasilkan bentuk baru yang masih memiliki kemiripan visual dengan objek yang dianalogikan. (Broadbent, 1973)

Suatu pendekatan analogi dikatakan berhasil apabila pesan yang ingin disampaikan atau objek yang dianalogikannya dapat dipahami oleh semua orang. Oleh karena itu, harus terdapat benang merah antara bangunan dan objek yang dianalogikannya dalam proporsi tertentu sehingga tidak menjadi terlalu naif seperti menjiplak secara mentah-mentah. Hal yang penting dalam analogi adalah persamaan antara bangunan dengan objek yang dianalogikan. Persamaan di sini bukan berarti benar-benar serupadengan objek dan hanya diperbesar ukurannya saja, tetapi yang dimaksudkan adalah persamaan berupa pesan yang disampaikan. Oleh sebab itu, analogi menjadi sangat berharga karena sifatnya yang sangat personal, berarti dapat dipahami oleh setiap orang. (Broadbent, 1973)

\subsection{Pengertian Wahana Apresiasi}

Menurut Sapardi Djoko Damono, wahana adalah medium yang dimanfaatkan atau dipergunakan untuk mengungkapkan sesuatu. Wahana adalah alat untuk membawa atau memindahkan sesuatu dari satu tempat ke tempat lain "sesuatu" yang dapat berupa gagasan, amanat, perasaan, atau sekadar suasana. (Moses)

Apresiasi yaitu suatu kegiatan menilai, menghargai, dan menelisik suatu karya baik itu seni maupun non-seni dengan berbagai cara, misalnya memberi panilaian, memberi kritik, mencoba, melakonkan, atau membuat suatu karya guna menginterpretasikan kegearan atau kesenangan terhadap suatu bidang / objek / karya. Bentuk dari apresiasi tersebut tentu berbeda-beda dari setiap individu yang menikmatinya. Sebab sense of beauty yang dimiliki setiap individu juga berbeda. Kegiatan apresiasi tersebut juga dilakukan untuk memberi nilai pada karya-karya seni yang telah diciptakan. (Al, 2019) 
Maka dapat disimpulkan wahana apresiasi merupakan wadah, sarana, atau tempat untuk mengevaluasi dan mengembangkan nilai estetika karya seni, meningkatkan dan mengembangkan kemampuan berkreasi dan berimajinasi, untuk menyempurnakan keindahan karya seni.

\subsection{Pengertian Seni Kontemporer}

Seni merupakan suatu karya buatan manusia yang unik atau berbeda dengan yang lain, yang memiliki maksud atau tujuan pembuatannya. Seni adalah suatu ekspresi perasaan manusia yang memiliki unsur keindahan di dalamnya dan diungkapkan melalui suatu media yang sifatnya nyata, baik itu dalam bentuk nada, rupa, gerak, dan syair, serta dapat dirasakan oleh panca indera manusia. (Maxmanroe.com)

Kata "Kontemporer" yang berasal dari kata "co" (bersama) dan "tempo" (waktu). Sehingga menegaskan bahwa seni kontemporer adalah karya yang secara tematik merefleksikan situasi waktu yang sedang dilalui. Atau pendapat yang mengatakan bahwa "seni rupa kontemporer" adalah seni yang melawan tradisi modernisme Barat. (setiawan, 2020)

Sederhananya, pengertian seni kontemporer yaitu seni yang "kekinian". Seni ini dibuat oleh orang masa kini yang masih hidup. Namun istilah „kekinian“ tidak dapat diartikan begitu saja, karena rincian-rincian yang ada di sekitar kata ini kadang rumit dan sulit dimengerti. Belum lagi pandangan setiap orang tentang istilah „kekinian “e bisa berbeda-beda. Seni kontemporer seringkali muncul karena respon terhadap dunia global yang memiliki budaya yang beragam dan teknologi yang maju. Seni kontemporer juga dapat menjadi cerminan atas masalah-masalah dunia modern yang kompleks saat ini. (Andaru, 2017)

\section{Metode Penelitian}

Jenis metode penelitian yang digunakan dalam Kajian Perancangan Wahana Apresiasi Seni Kontemporer ini adalah menggunakan metode kualitatif dimana dalam metode ini sangat mengandalkan analisis data dari survey studi kasus lapangan dan literatur. Metode kualitatif adalah metode riset yang sifatnya memberikan penjelasan dengan menggunakan analisis. Pada pelaksanaannya, metode ini bersifat subjektif dimana proses penelitian lebih diperlihatkan dan cenderung lebih fokus pada landasan teori.

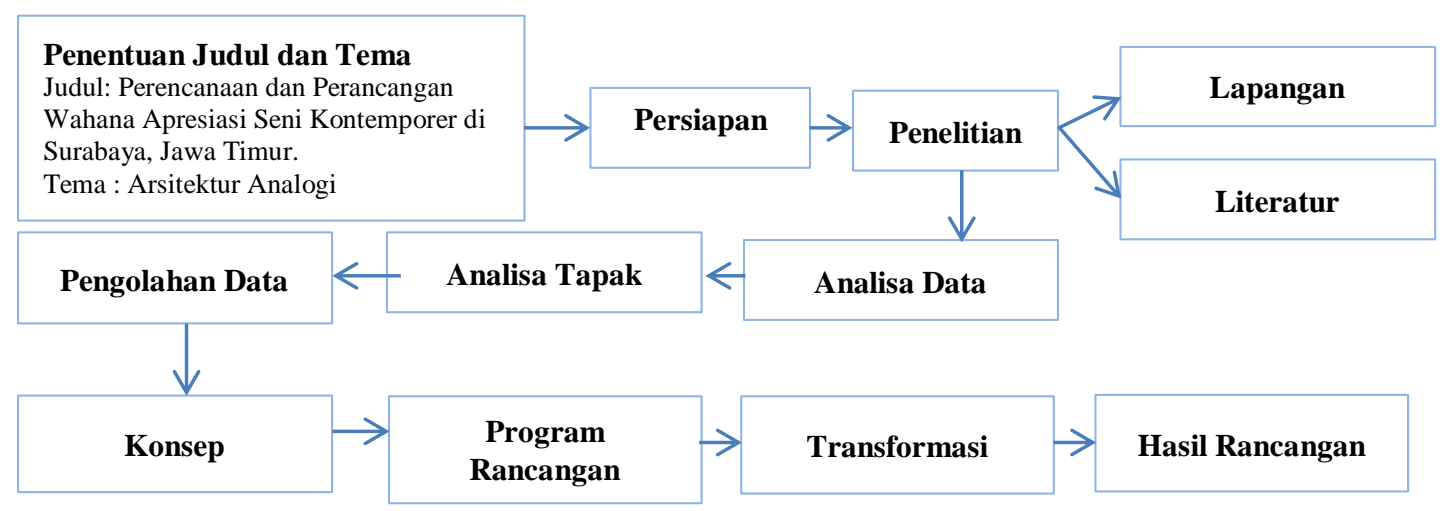

Gambar 1. Diagram Metode Penelitian

\section{Pembahasan}

\subsection{Studi Banding}

Hasil observasi studi banding secara lapangan dan literatur menghasilkan data yang dapat digunakan untuk merancang dan atau membuat program ruang serta desain pada rancangan ini. Studi banding lapangan dilakukan di Museum MACAN dan Galeri Nasional di Jakarta. Studi banding literature menggunakan Museum Gunung Merapi di Yogyakarta dan Museum Tsunami di Aceh. 


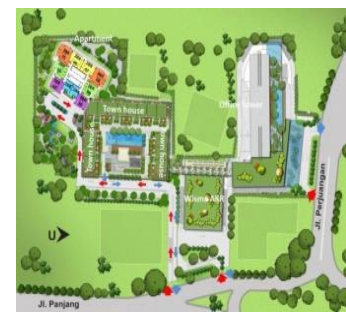

(a)

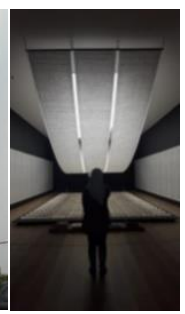

(c)

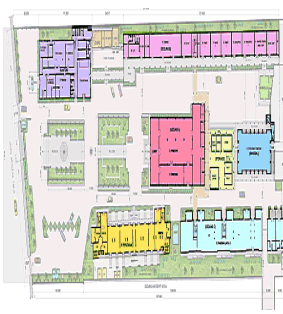

(d)

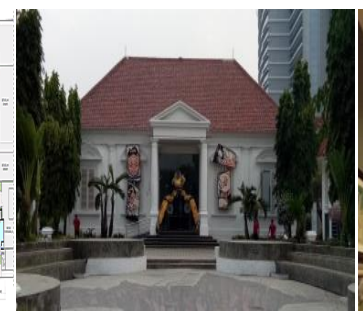

(e)

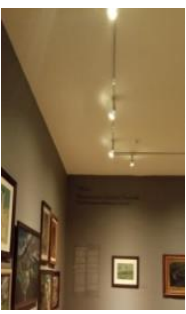

(f)

Gambar 2. Studi Banding Lapangan (a)(b)(c) Tatanan Lahan, Bentuk, Ruang Museum MACAN (d)(e)(f)Tananan Lahan, Bentuk, Ruang Galeri Nasional

Sumber : (a) https://www.google.com/image diakses 19 Nopember 2019 (b)(c)data pribadi, 2019 (d) http://galerinasional.or.id/halaman/facility, diakses 20 Nopember 2019 (e)(f)data pribadi, 2019

Tatanan lahan pada museum macan bersifat efisien untuk fungsi komplek gedung. Letak parkir yang tidak dekat dengan Main Entrance bisa di tunjang dengan adanya pedestrian yang indah sehingga pangunjung tetap merasa senang walaupun harus berjalan kaki. Aspek bangunan dan bentuk bangunan pada AKR Tower tidak mempresentasikan adanya Museum Seni Kontemporer didalamnya. Hal ini dikarenakan tergabung dalam fungsi bangunan yang lebih dahulu ada disbanding perencanaan Museum itu sendiri. Aspek ruang pada Museum Macan sangat unik. Aksesibilitas pengunjung dan pengelola sangat berbeda tetapi tidak menjadi suatu permasalahan dalam tatanannya. Setiap ruang didalamnya memiliki latar suasana yang berbeda dengan instalasi ruang yang fleksible. Aspek struktur bangunan pada bangunan ini menggunakan core dan shearwall, serta ada beberapa kolom pendukung. Hal ini dinilai sangat efektif dalam fungsi bangunan sehingga dapat menampilkan karya seni dengan leluasa.

Tatanan lahan pada Galeri Nasional memiliki konsep Efektif dengan pengaturan parkir, loading dock, main entrance, dan drop off area yang baik. Aspek bentuk bangunan pada Galeri Nasional memiliki bentuk berlanggan Neo-Klasik. Aspek ruang pada Galeri Nasional ini tidak menyatu dengan ruang luar dan fasade bangunan yang berlanggan Neo-Klasik, ruang ruang pada galeri ini memiliki tema dan konsep masing masing sesuai fungsinya. Sains bangunan seperti pencahayaan dan penghawaan buatan idak terlalu diperhatikan pada ruang dalam. Kebanyakan menggunakan pencahayaan dan penghawaan buatan agar bisa diatur sesuai suasana yang diinginkan. Struktur bangunan menggunakan kolom dan balok seperti halnya bangunan low rise pada umumnya.

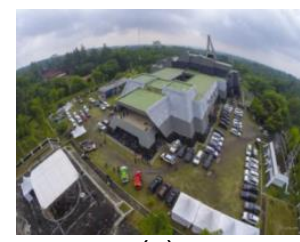

(g)

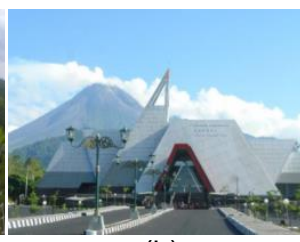

(h)

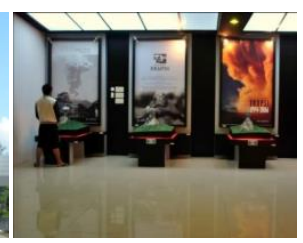

(i)

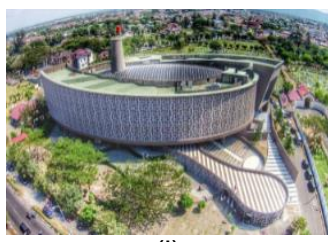

(j)

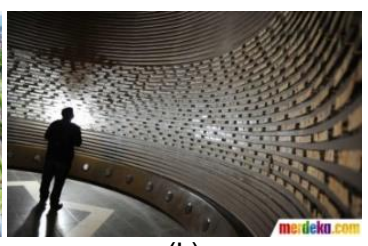

$(\mathrm{k})$

Gambar 3. Studi Banding Literatur (g)(h)(i) Tatanan Lahan, Bentuk, Ruang Museum Gunung Merapi (j)(k)Bentuk, Ruang Museum Tsunami Aceh

Sumber: $(g)(h)(i)$ http://e-journal.uajy.ac.id/11419/4/TA142823.pdf diakses 19 Nopember $2019(j)(k)$ https://docplayer.info/71606708-Makna-arsitektur-teori-estetika-dan-perilaku.html diakses 13 Januari 2020

Penataan tapak masih memperhatikan tata hijau serta alur sirkulasi kendaraan yang memutar. menggunakan konsep minimalis dan efisien bagi pengunjung. 2 jalan kembar di depan bangunan sebagai penunjuk arah. Setelahnya pengunjung parkir di tempat yang sudah disediakan mengelilingi bangunan. Bangunan terlihat kokoh menyerupai bentuk gunung. Gubahan massa berasal dari bentuk gunung, dan menjadi ikon merapi di daerah Sleman. Ruang dalam bangunan memiliki konsep dan suasana yang diciptakan sendiri sendiri sesuai dengan penyajian karya seninya.

Tatanan lahan pada museum Tsunami Aceh ini memiliki alur sirkulasi kendaraan memutar. Bentuk bangunan diambil penganalogian bentuk rumah panggung dan kapal penyelamatan. Ruang ruang pada bangunan memiliki latar suasana yang berbeda beda dan maksud yang berbeda beda pula. Bangunan memiliki void yang lumayan besar difungsikan untuk pencahayaan dan penghawaan alami. 
Tetapi setiap ruangan di dalam bangunan memiliki pencahayaan dan penghawaan buatan sendiri untuk menghadirkan suasana yang pas bagi pengunjung didalam ruangan. Struktur bangunan pada bangunan ini didominasi oleh balok dan kolom yang terlihat seperti menopang panggung, serta penggunaan core yang berbentuk tabung berdada di tengah tengah bangunan menjulang keatas.

\subsection{Program Ruang}

Metode penyusunan program ruang dalam perancangan Wahana Apresiasi Seni Kontemporer ini adalah dengan melibatkan kelebihan dan kekurangan dari data analisis studi kasus lapangan dan studi kasus literature yang mencakup aktivitas, ruang gerak, luasan, serta volume ruang. Pada rancangan ini dibagi beberapa fasilitas diantaranya fasilitas utama, penunjang, pengelola, dan servis.

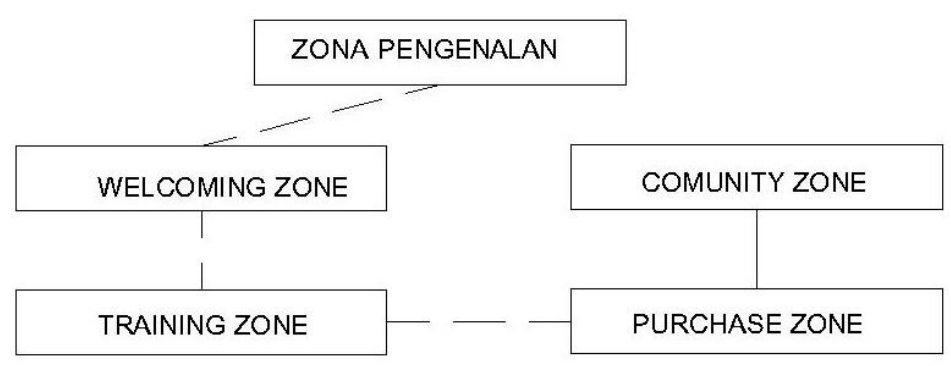

Gambar 4. Organisasi Ruang Makro

\begin{tabular}{|l|l|l|l|l|l|l|l|}
\hline AKUSTIK & $\begin{array}{l}\text { PENCAHA } \\
\text { YAAN } \\
\text { BUATAN }\end{array}$ & $\begin{array}{l}\text { PENCAHA } \\
\text { YAAN } \\
\text { ALAMI }\end{array}$ & $\begin{array}{l}\text { KETENA } \\
\text { NGAN }\end{array}$ & $\begin{array}{l}\text { PENGHA } \\
\text { WAAN } \\
\text { BUATAN }\end{array}$ & $\begin{array}{l}\text { PENGHA } \\
\text { WAAN } \\
\text { ALAMI }\end{array}$ & JENIS RUANG & ZONING \\
\hline$\checkmark$ & $\checkmark$ & $\checkmark$ & $\checkmark$ & & FASILITAS UTAMA & FUBLIK \\
\hline & $\checkmark$ & $\checkmark$ & & $\checkmark$ & $\checkmark$ & FASILITAS PENUNIANG & FRIVAT \\
\hline & $\checkmark$ & & & $\checkmark$ & $\checkmark$ & FASILITAS PENGELOLA & FASIVAT \\
\hline
\end{tabular}

\subsection{Lokasi}

Gambar 5. Hubungan Ruang Makro

Lokasi tapak yang terpilih terletak di Jl. Dr. Ir. Hj. Soekarno, Penjaringan Asri, Rungkut, Surabaya yang memiliki luas lahan 3,5 hektar. Alasan pemilihan lahan karena memenuhi persyaratan ruang lingkup dengan peruntukkan lahan sebagai area komersil. Selain itu, lokasi ini dipilih karena sangat strategis dan berdekatan dengan banyak fasilitas public.

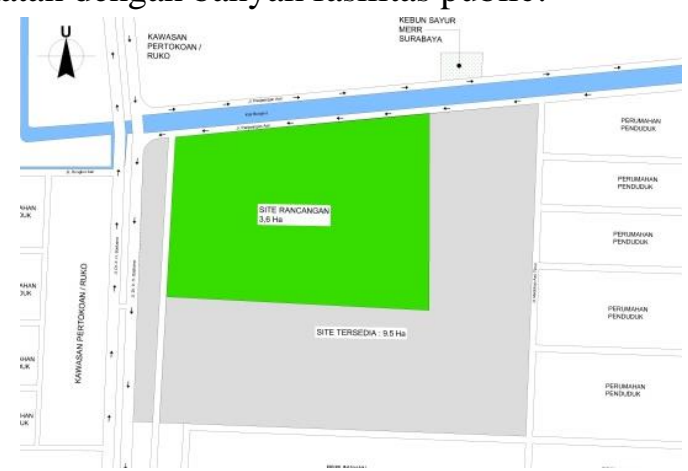

Gambar 6. Lokasi Tapak Terpilih

\subsection{Konsep}

Konsep mikro tatanan lahan yaitu "Terintegrasi" dimana mewujudkan penataan massa yang teratur serta jelas menurut zona dan fungsinya, serta dimaksudkan agar sirkulasi pengunjung terarah dari awal masuk sampai keluar. Transformasi penataan lahan melalui zoning yang didapat, lalu diwujudkan 
kedalam tatanan massa bangunan yang memperhatikan lingkungan sekitar sehingga dapat memberi dampak positif kedalam tapak serta bangunan.

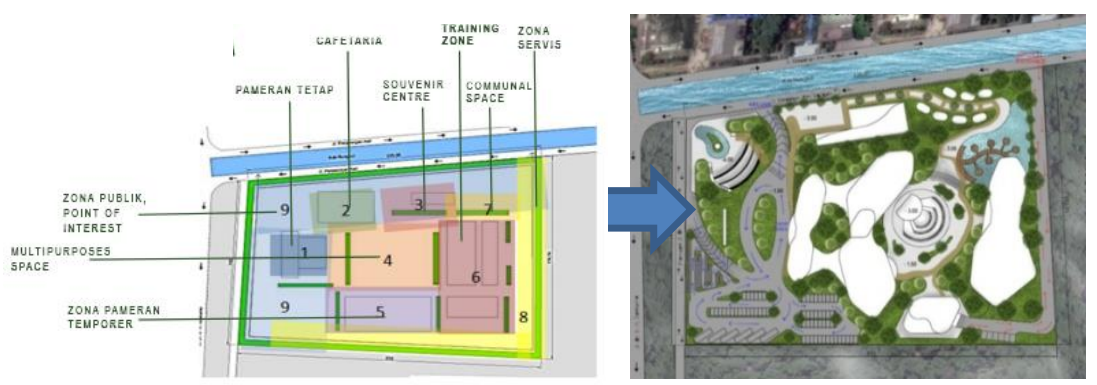

Gambar 7. Transformasi Tatanan Lahan

Konsep mikro bentuk yang dipilih adalah "Dinamis" yaitu konsep yang mewujudkan bangunan yang menarik dan tidak membosankan dengan menggunakan analogi seni kontemporer yang memiliki sifat bebas, serta baru lahir dan berkemang. Perkiraan bentuk bangunan yang menganalogikan bentuk 'tunas' yang baru muncul di tanah. Tunas dipilih karena menganalogikan seni kontemporer yang masih berkembang hingga sekarang, sehingga perlu adanya pengenalan dan pengapresiasian agar tidak mati.
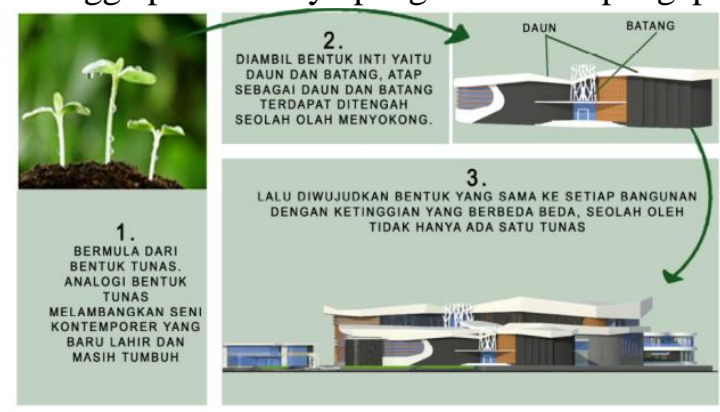

Gambar 8. Transformasi Bentuk

Konsep mikro ruang "Fleksibel" memiiki maksud myediakan ruang seni yang tidak tetap, dan dapat diubah-bah enataan dan instalasinya sehingga dapat menyuguhkan kesenian kontemporer dalam bentuk apapun. Ruang dirancang dengan space besar tetapi dapat fleksible terbagi atas beberapa bagian sesuai dengan kebutuhan ruang instalasi seninya. Konsep fleksible dipilih dengan tujuan agar ruangan dapat dipakai oleh berbagai jenis seni kontemporer.

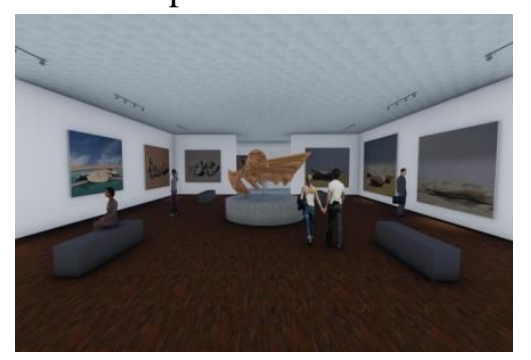

Gambar 9. Ide Ruang Dalam

\section{Hasil Rancangan}

Pertimbangan desain tatanan lahan diperoleh dari hasil analisa tapak baik internal maupun eksternal yang menghasilkan pembagian zoning dan dilanjukan dengan pembuatan blokplan yang mengacu kenyamanan dan keamanan. Bentuk massa dihadirkan mirip dengan benuk daun pada tunas untuk memperkuat penganalogian bentuk kedalam bentuk tunas. Pada layout diperlihatkan rancangan denah pada lantai dasar setiap bangunan. Dari layout bisa terlihat dengan jelas arah sirkulasi pengunjung dari masuk sampai keluar.
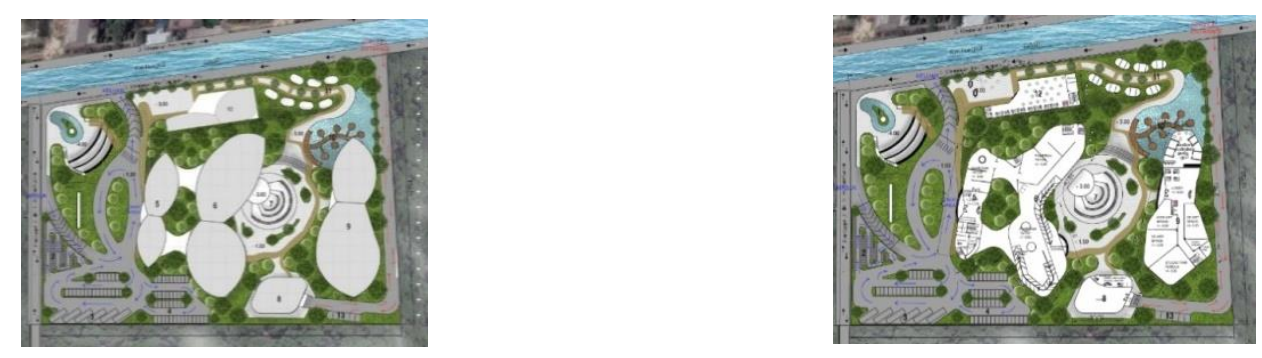
(l)

Gambar 10. (l)Blockplan (m)Siteplan

(m)

Desain bangunan yang dinamis merupakan perwujudan konsep kontemporer ke dalam bentuk bangunan. Bangunan dibentuk dengan sifat sifat kontemporer yang bebas, dinamis, tidak monoton, tetapi tetap menganalogikan penganalogian bentuk tunas.

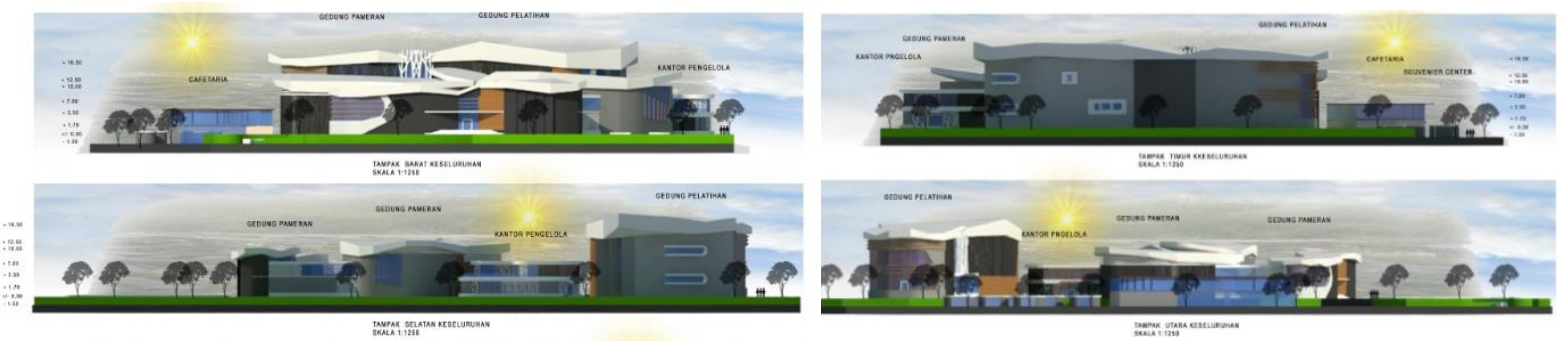

Gambar 11. Tampak Keseluruhan Bangunan

Tampak barat merupakan fasade depan bangunan yang akan terlihat dari jalan utama, dirancang dengan dominasi warna hitam, abu, dan aksen kayu. Serta ornamen ornamen kontemporer berbentuk dinamis. Atap berbentuk dinamis menyerupai bentuk daun. Tampak timur merupakan tampak dari pada bagian belakang bangunan sehingga tidak terdapat banyak ornamen seperti tampak depan, warna didominasi dengan hitam dan abu-abu. Tampak utara merupakan tampak yang terlihat dari jalan Penjaringan Asri. Tampak timur didominasi dengan fasade cafetaria yang menggunakan kaca bening dan aksen batu alam berwarna putih. Tampak selatan bangunan ddominasi dengan warna abu-abu dan putih pada ornamen jendela.

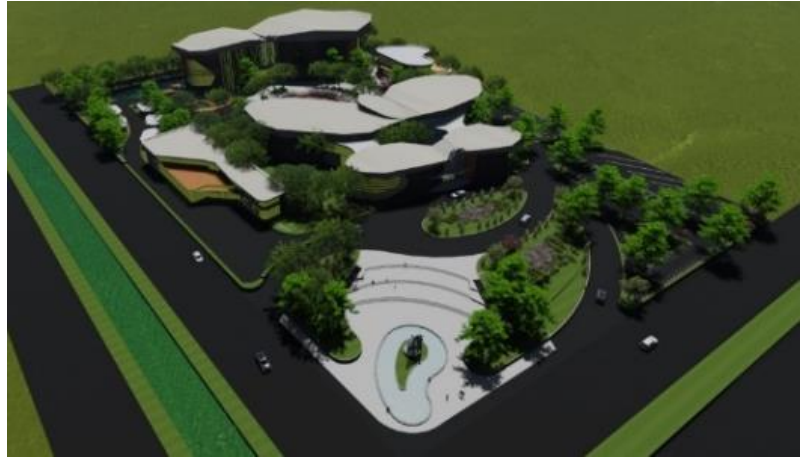

Gambar 12. Perspektif Mata Burung

Pada potongan site, terlihat jelas dengan keterangan struktur utama bangunan yaitu kolom dan balok, serta pondasi tiang pancang. Juga penggunaan atap space frame pada sebagian bangunan, dan penggunaan atap dak pada sebagian bangunan.
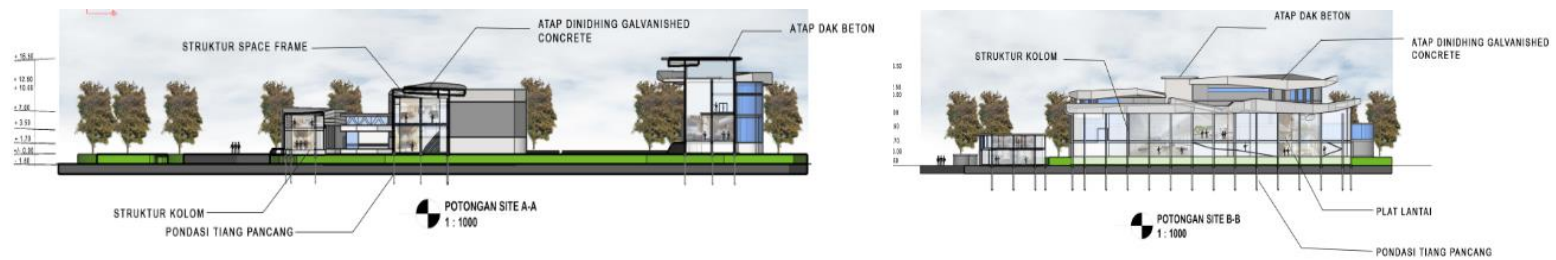

Gambar 13. Potongan Keseluruhan 
Interior Ruang Pameran Temporer bersifat fleksible. Penataan ruang disesuaikan dengan kebutuhan karya seni itu sendiri. Karya seni dan tata ruang akan diubah setiap periode berganti (temporer), dan akan diganti dengan penataan dan karya seni baru.

Instalasi penunjang yang digunakan pada ruang juga yang bersifat temporer atau bisa diubah ubah, seperti penggunaan papan sebagai sekat, penggunaan lampu sorot sebagai pencahayaan serta efek pada karya seni (arah sorotnya dapat diubah).

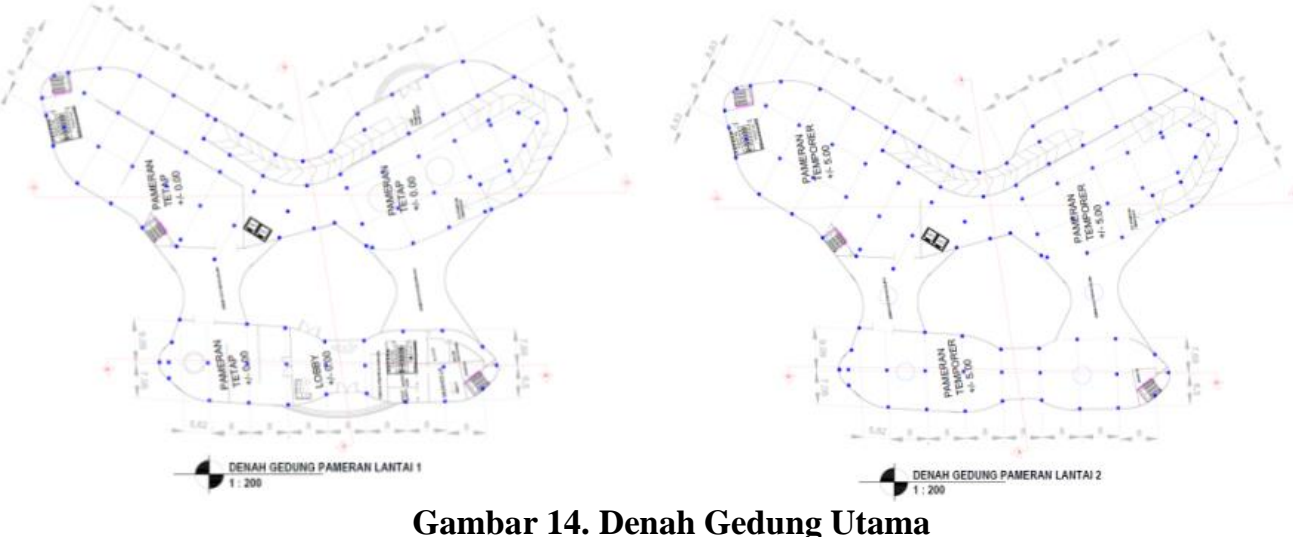

Gambar 14. Denah Gedung Utama

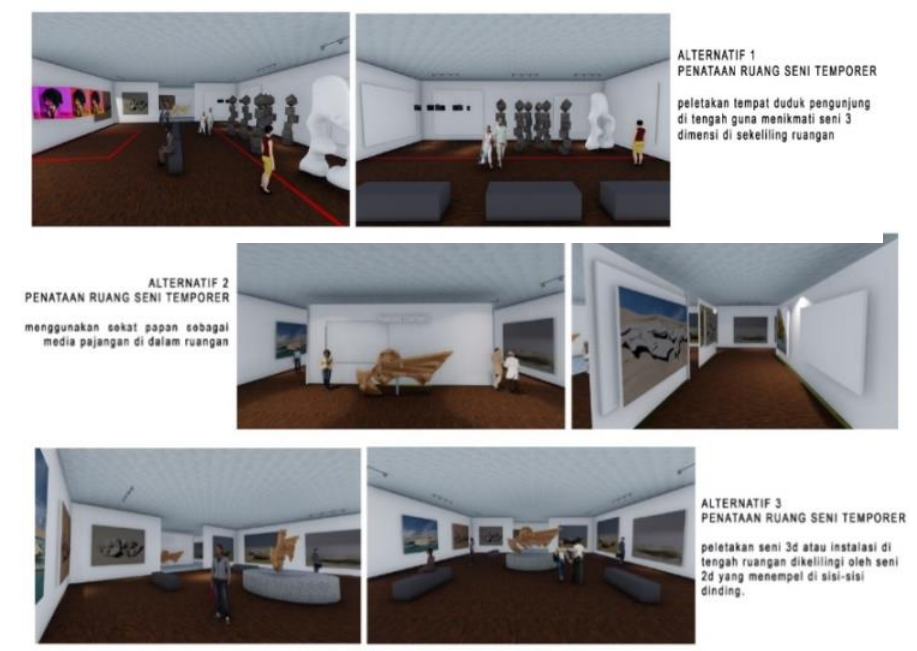

Gambar 15. Interior Ruang Pameran Temporer

\section{Kesimpulan}

Wahana Apresiasi Seni Kontemporer merupakan sebuah sarana-prasarana yang diperuntukkan bagi para pecinta dan penikmat seni, khususnya seni kontemporer, untuk menghadirkan seni atau sekedar mengapresiai seni-seni kontemporer. Didesain dengan maksud untuk menyediakan wadah bagi masyarakat khususnya Kota Surabaya untuk dapat ikut serta mengapresiasi karya seni masa kini atau seni kontemporer baik dari dalam maupun luar negeri. Lokasi lahan yang dipilih dalam merancang Wahana Apresaisi Seni Kontemporer terletak di jalan Merr atau Jl. Dr. Ir. H. Soekarno, Penjaringan Sari, Rungkut, Surabaya Timur, Kota Surabaya. Alasan pemilihan lahan karena memenuhi persyaratan ruang lingkup dan batasan-batasan proyek yang sudah ditentukan sebelumnya.

Proyek ini didesain menggunakan arsitektur analogi yang mengekspresikan wujud seni kontemporer sebagai wujud dan fungsi bangunan serta ruang pada bangunan yang menyiratkan sifat sifat seni kontemporer yakni tidak terikat, dinamis, serta berkembang sesuai zaman. Konsep mikro Terintegrasi pada tatanan lahan mewujudkan penataan massa yang teratur serta jelas menurut zona dan fungsinya. Ini dimaksudkan agar sirkulasi pengunjung terarah dari awal samai keluar sehingga tidak melewatkan satupun sajian seni. Konsep Mikro Dinamis pada bentuk bangunan mewujudkan bentuk bangunan yang menarik dan tidak membosankan dengan menggunakan analogi seni kontemporer yang 
memiliki sifat bebas, serta baru lahir dan berkembang. Konsep mikro Fleksibel pada ruang dimaksudkan menyediakan ruang seni yang fleksibel, tidak tetap, dan dapat diubah-ubah penataan dan instalasinya sehingga dapat menyuguhkan kesenian kontemporer dalam bentuk apapun.

\section{Referensi}

Al, Y. (2019). Apresiasi Seni. from https://www.eduspensa.id/apresiasi-seni

Andaru, P. D. (2017). Pengertian Seni Kontemporer, Sejarah dan Macamnya.

Broadbent, G. (1973). Design in Architecture : Architecture and the Human Sciences.

Lucia Ina Trisjanti, H. P., Muhammad Faqih. PENGGUNAAN ANALOGI SEBAGAI METODA RANCANG ARSITEKTUR.

Maxmanroe.com. Pengertian Seni: Fungsi, Tujuan, dan Macam-Macam Seni. from https://www.maxmanroe.com/vid/umum/pengertian-seni.html

$\begin{array}{llllll}\text { Moses, } & \text { F. } & \text { Alih } & \text { Wahana } & \text { Dalam } & \text { Sastra. }\end{array}$ http://badanbahasa.kemdikbud.go.id/lamanbahasa/artikel/2773/alih-wahana-dalam-sastra

Setiawan, s. (2020). Seni Rupa Kontemporer - Pengertian, Ciri, Keunikan, Apresiasi, Macam, Contohnya. from https://www.gurupendidikan.co.id/seni-rupa-kontemporer 
